\title{
Perancangan Manajemen Bandwidth Dan Block Access Website Berdasarkan User Di Mikrotik Pada Ananda Islamic School
}

\author{
Yuliadi $^{l}$ \\ yuliadi_95@yahoo.com ${ }^{1}$
}

Jurusan Teknik Informatika, Prodi Teknik informatika ${ }^{1}$

\begin{abstract}
The development of computer networks today is very influential on human life, especially in the world of work and education. Almost all activities now require computer networks. Computer networks can help humans to work optimally and efficiently. Ananda Islamic School uses ISP (Internet Service Provider) from ATS (Asia Technology Solutions) with a bandwidth of $20 \mathrm{Mbps}$ where all users, including Bod and School Principals, ave access rights to use the same bandwidth to the internet network so there will be a density when all users in he institution access the internet intensely at the same time. In addition to the bandwidth problem, there are other problems with this institution's network, namely the existence of users who use the internet not to access learning needs during study hours. There are still many users who use the internet to access social media sites like facebook, Twitter and others. Of the various problems, it is necessary to design a network system and settings for bandwidth management, block website user access. The newest network will use Mikrotik RouterBoard to manage bandwidth, block the user's website access block. The expected result is a network that has a stable bandwidth and blocking certain user websites in the study hours for the achievement of productivity in the use of the internet.
\end{abstract}

\section{Article History}

Received 2020-10-29

Revised 2020-11-12

Accepted 2020-11-19

\section{Key words}

Automation

System

Algorithm .. - font 9

\begin{abstract}
ABSTRAK
Perkembangan jaringan komputer saat ini sangatlah berpengaruh terhadap kehidupan manusia, khususnya di dunia kerja maupun pendidikan. Hampir semua kegiatan sekarang membutuhkan jaringan komputer. Jaringan komputer dapat membantu manusia untuk bekerja secara maksimal dan efisien. Ananda Islamic School menggunakan ISP (Internet Service Provider) dari ATS (Asia Teknologi Solusi) dengan bandwidth 20 Mbps dimana semua user, termasuk Bod dan Kepala Sekolah memiliki hak akses penggunaan bandwidth yang sama terhadap jaringan internet sehingga akan terjadi kepadatan saat semua pengguna dalam lembaga tersebut mengakses internet secara intens dalam waktu bersamaan. Selain masalah bandwidth, terdapat masalah lain pada jaringan lembaga ini, yaitu adanya user yang menggunakan internet tidak untuk mengakses kebutuhan pembelajaran di jam belajar. Masih banyak user yang menggunakan internet untuk mengakses situs-situs social media seperti facebook, twitter maupun lainnya. Dari berbagai masalah tersebut, maka diperlukan perancangan sistem jaringan serta pengaturan untuk bandwidth management, block access website user. Jaringan yang terbaru akan menggunakan Mikrotik RouterBoard untuk melakukan bandwidth management, pengaturan block access website user. Hasil yang di harapkan adalah jaringan yang memiliki bandwidth yang stabil dan pemblokiran website user tertentu di jam belajar demi tercapainya produktifitas dalam penggunaan internet
\end{abstract}

\section{PENDAHULUAN}

Perkembangan jaringan komputer saat ini sangatlah berpengaruh terhadap kehidupan manusia, khususnya di dunia kerja maupun pendidikan. Hampir semua kegiatan sekarang membutuhkan jaringan komputer. Jaringan komputer dapat membantu manusia untuk bekerja secara maksimal dan efisien. Untuk terhubung dengan internet, Local Area Network (LAN) harus terintegrasi dengan salah satu layanan internet yang disediakan Internet Service Provider (ISP). ISP akan memberikan bandwidth sesuai dengan kebutuhan. Namun, apabila penggunaan internet 
semakin banyak maka akan terjadi kemacetan pada lalu lintas jaringan yang menyebabkan kecepatan akses internet menurun.

Ananda Islamic School merupakan suatu instansi dibidang lembaga pendidikan yang memiliki sebuah jaringan internet yang digunakan untuk transmisi data, media pembelajaran dan mencari informasi. Koneksi internet pada Ananda Islamic School menggunakan ISP (Internet Service Provider) dari ATS (Asia Teknologi Solusi) dengan bandwidth 20 Mbps dimana semua user, termasuk Bod dan Kepala Sekolah memiliki hak akses penggunaan bandwidth yang sama terhadap jaringan internet sehingga akan terjadi kepadatan saat semua pengguna dalam lembaga tersebut mengakses internet secara intens dalam waktu bersamaan.

Selain masalah bandwidth, terdapat masalah lain pada jaringan lembaga ini, yaitu adanya user yang menggunakan internet tidak untuk mengakses kebutuhan pembelajaran di jam belajar. Masih banyak user yang menggunakan internet untuk mengakses situs-situs social media seperti facebook, twitter maupun lainnya.

Oleh karena itu, dibutuhkan block access user untuk memblokir website dan untuk mengatasi masalah bandwidth, dibutuhkan manajemen bandwidth sehingga bandwidth dapat digunakan dengan lebih efisien sesuai dengan kebutuhan setiap user-nya. Salah satu metode manajemen bandwidth yang dapat diterapkan adalah queue tree. Metode manajemen bandwidth ini dapat diterapkan sesuai dengan prioritas dalam struktur lembaga pendidikan .

Untuk mengatasi permasalahan mendapatkan bandwidth dengan kadar atau ukuran yang sama tanpa mengganggu bandwidth dari user/host yang lain, perlu dibangun sebuah system untuk memanajemen bandwith menggunakan Queue Tree pada router Mikrotik. yang berfungsi untuk membagi bandwith yang di butuhkan masing-masing unit komputer agar dapat memaksimalkan penggunaan internet [1].

Perlu adanya sebuah sistem yang akan mengatur konfigurasi server internet di sekolah seperti menerapkan network police supaya penggunaan internet disekolah lebih baik dengan cara membatasi pengaksesan beberapa situs [2].

Perlu diterapkan sebuah metode filtering yang dapat mengklasifikasikan paket-paket yang masuk dan keluar pada sebuah jaringan dengan port non standar dan standar. Packet classifier yang mengoperasikan sebuah set aturan dimana masing-masing aliran mematuhi setidaknya satu aturan [3].

\section{TINJAUAN PUSTAKA}

\section{Port Internet}

Sebuah port internet adalah mekanisme yang mengizinkan sebuah komputer untuk mendukung beberapa sesi koneksi dengan komputer lainnya dan program di dalam jaringan. Port dapat mengidentifikasikan aplikasi dan layanan yang menggunakan koneksi di dalam jaringan TCP/IP, port dapat dikenali dengan angka 16-bit (dua byte) [4].

\section{Bandwidth}

Bandwidth adalah suatu besaran yang menunjukkan seberapa banyak data dapat dilewatkan dalam koneksi melalui sebuah network. Istilah ini berasal dari bidang teknik listrik, di mana bandwidth yang menunjukkan total jarak atau berkisar antara tertinggi dan terendah sinyal pada saluran komunikasi (band) [1] .

\section{Layer 7 Protocol}

Artikel merupakan sumber teks terstruktur yang nantinya dibaca dan sebagai sumber referensi oleh subjek peneliti lainya. Penyajian data dan estetika layout dalam bentuk tabel, gambar, diagram alir dan elemen artikel lain harus representatif, sehingga memudahkan dalam proses editing dan penerbitan. Layout artikel yang terdapat dalam file template ini, bisa langsung digunakan oleh penulis (author) dalam artikel JURNAL KERNEL. Ukuran kertas adalah A4, dengan batas pinggir (atas: $3 \mathrm{~cm}$ | bawah: $2.5 \mathrm{~cm}$ | kiri: $3 \mathrm{~cm} \mid$ kanan: $2.5 \mathrm{~cm}$ ), spasi 1, dan satu kolom [7]. Setting kertas mirror margin karena nantinya akan dicetak halaman bolak-balik. Jumlah naskah 6-8 halaman (maksimum 8 halaman), Menggunakan font times new roman, file dikirim dalam bentuk ekstensi $*$ doc atau $*$ docx - pihak redaksi tidak menerima file LateX, atau *pdf, dan seluruh 
gambar diformat dalam bentuk GREYSCALE - karena mempertimbangkan pencetakan buku hitam putih. Referensi menggunakan standart citation style IEEE [3].

\section{IP Address}

IP Address adalah suatu identitas numerik yang dilabelkan kepada suatu alat seperti komputer, router atau printer yang terdapat dalam suatu jaringan komputer yang menggunakan internet protocol sebagai sarana komunikasi [5].

\section{METODE}

\section{Observasi}

Pada metode ini penulis langsung melakukan pengamatan langsung pada Ananda Islamic School untuk mengatahui informasi, permasalahan yang di butuhkan oleh penulis.

\section{Wawancara}

Dalam wawancara ini dilakukan tanya jawab dengan bapak Rizal selaku Crew IT pada Ananda Islamic School untuk mendapatkan informasi terhadap permasalahan jaringan komputer pada Ananda Islamic School.

\section{Studi Pustaka}

Penulis melakukan metode studi pustaka sebagai pendukung untuk mendapatkan berbagai macam informasi dengan cara mencari buku dan jurnal yang terkait dengan pembahasan sebagai referensi dalam penulisan skripsi ini.

\section{HASIL DAN PEMBAHASAN}

\section{Hasil}

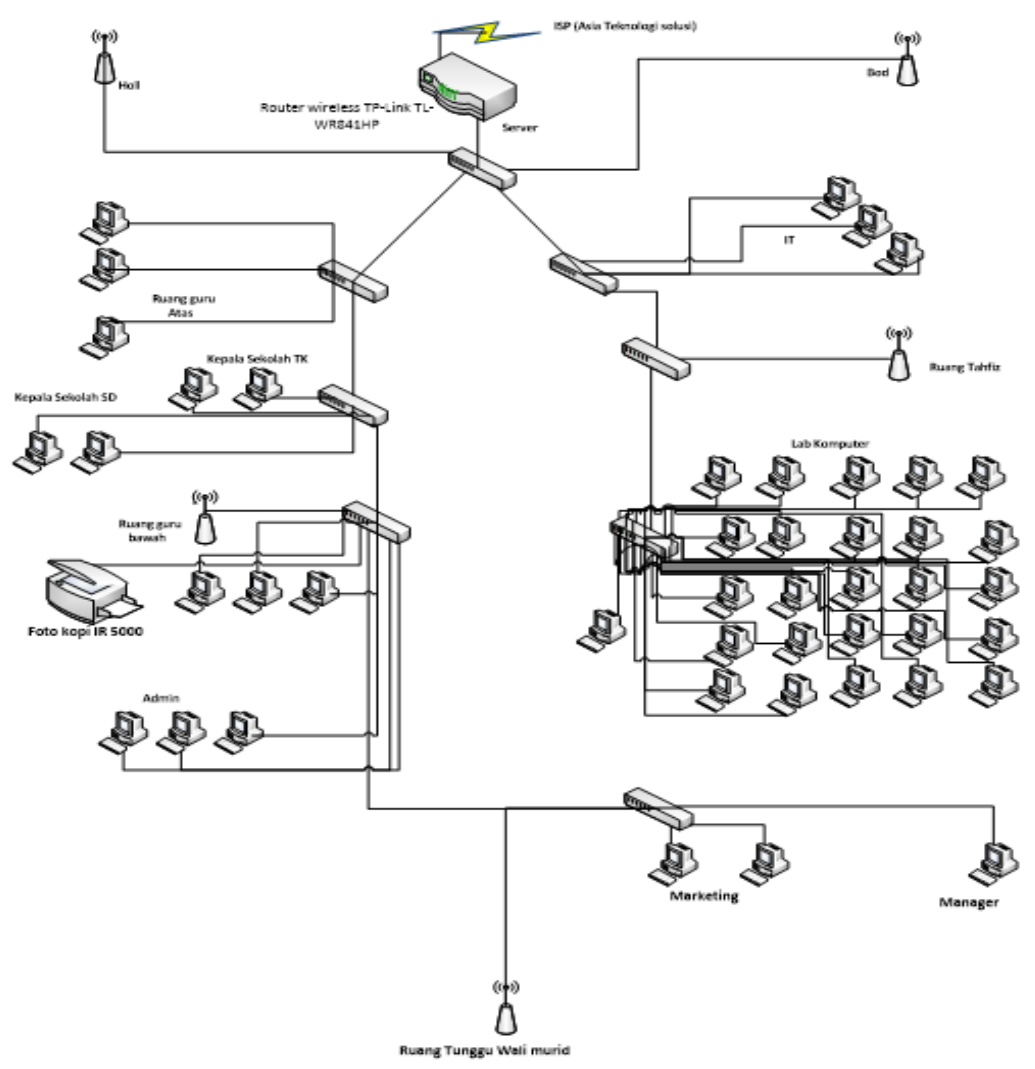

Gambar 1. Topologi jaringan berjalan AIS 
Ananda Islamic School memiliki jaringan komputer dalam mendukung kinerja semua user dalam pembelajaran. Topologi jaringan berjalan pada kantor Ananda Islamic School menggunakan topologi tree, karena mempunyai 8 switch dan setiap client dikelompokkan dengan switch/hub sebagai pusat komunikasi. Arsitektur jaringan komputer pada Ananda Islamic School untuk dapat terhubung dengan internet yaitu berasal dari ISP ATS (Asia Teknologi Solusi) dengan bandwidth up to $20 \mathrm{Mbps}$. Router utama menjadi gateway untuk menghubungkan jaringan local dengan internet dan juga sebagai DHCP server agar semua perangkat mendapat IP Address secara otomatis. IP Address yang digunakan yaitu IP Address kelas B.

\section{Pembahasan}

Untuk sistem jaringan komputer yang diusulkan penulis melalui router mikrotik RB 951UI2HnD pada Ananda Islamic School diantaranya sebagai berikut:

a. Setiap user agar bisa internet harus memasukkan username dan password yang sudah disetting sebelumnya dalam mikrotik.

b. Setip user memiliki kecepatan bandwith yang berbeda-beda maupun setiap user terblokir website-nya dijam dan hari tertentu.

Dengan menggunakan router mikrotik RB 951UI-2HnD dan software winbox dapat mempermudah administrator jaringan dalam mengelola, memonitoring sebuah jaringan kompute.

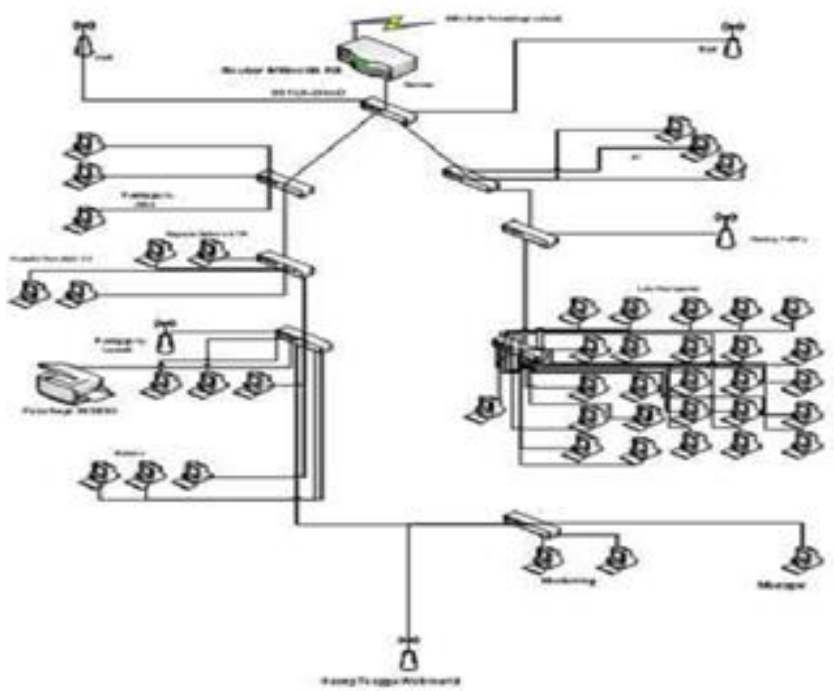

Gambar 2. Topologi jaringan usulan

Untuk topologi jaringan masih menggunakan topologi jaringan tree seperti jaringan yang sudah berjalan, tetapi ada sedikit perubahan untuk Router TP-Link TL-WR841HP diganti dengan Router Mikrotik RB 951UI-2HnD. Agar keamanan yang menyangkut data-data disetiap PC user lebih aman maupun pembagian bandwith lebih mudah dan merata. Begitu pula dengan IP address yang awalnya IP kelas B dirubah IP kelas A karena menyangkut semakin banyaknya client setiap tahunnya semakin bertambah.

Berikut tampilan rancangan sistem jaringan komputer yang penulis buat pada Ananda Islamic School menggunakan router mikrotik RB 951UI-2HnD dan software winbox: 


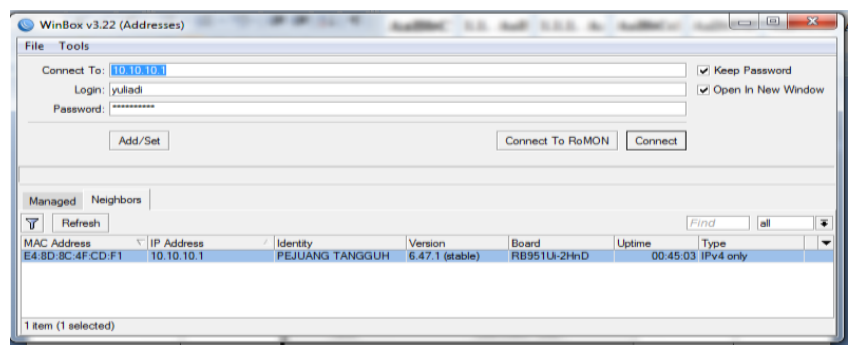

Gambar 3. Login winbox mikrotik

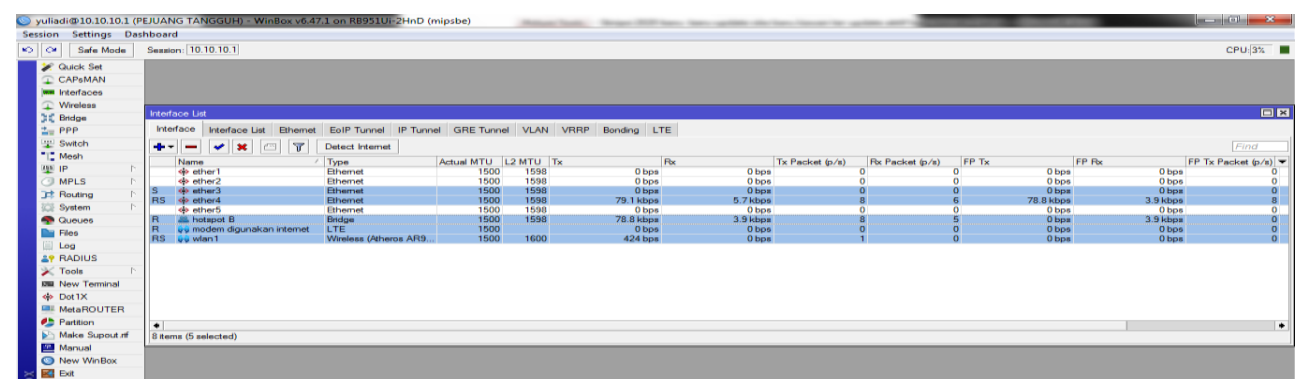

Gambar 4. Interface list

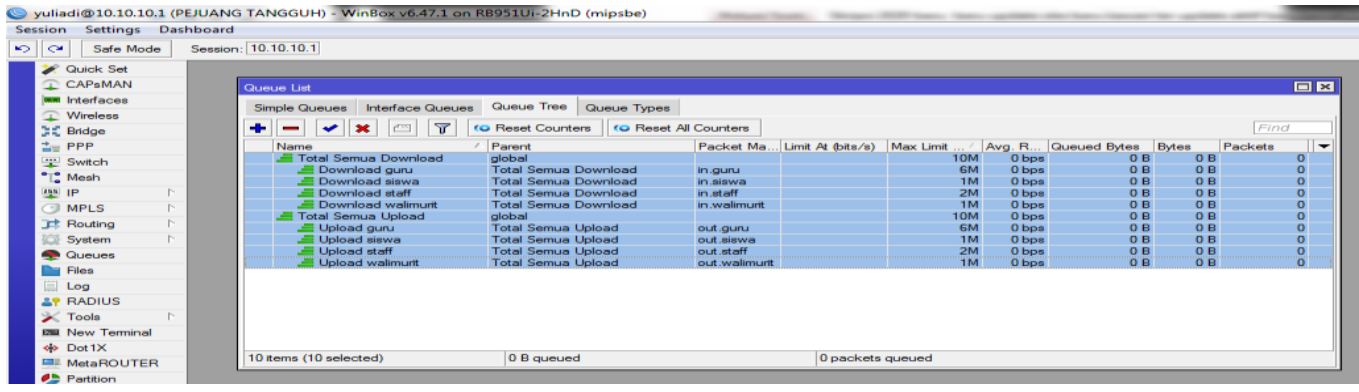

Gambar 5. Hasil manajemen bandwith queue tree

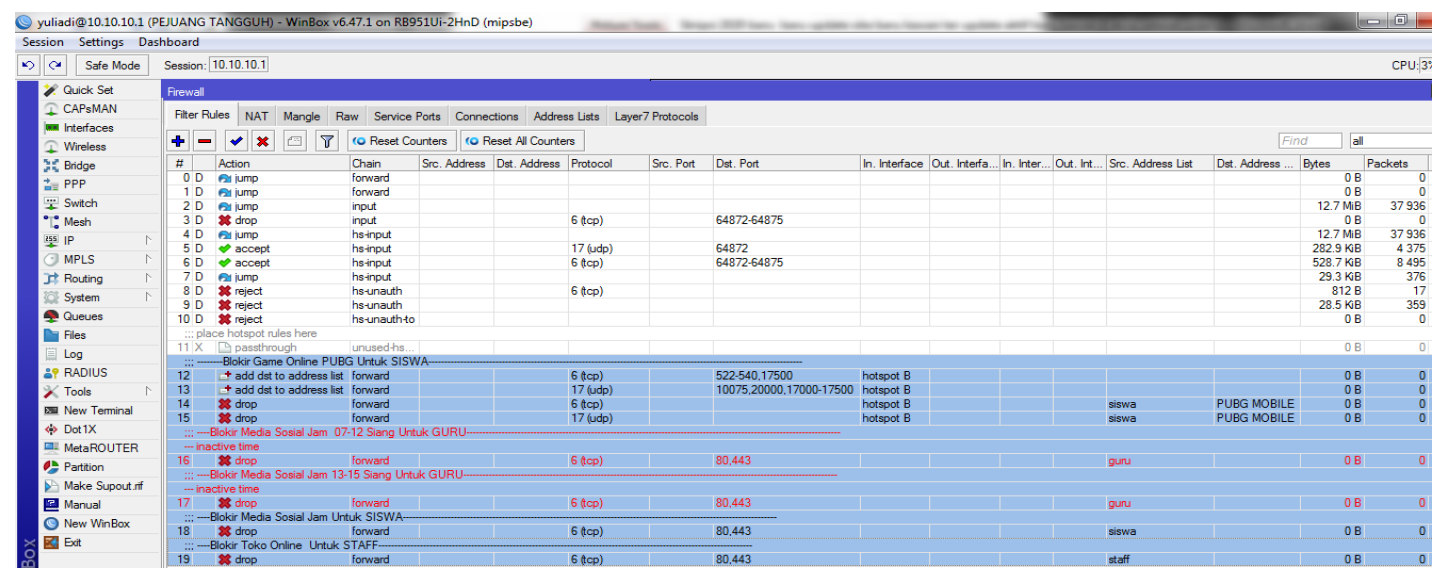

Gambar 6. Hasil pembuatan firewall rule 


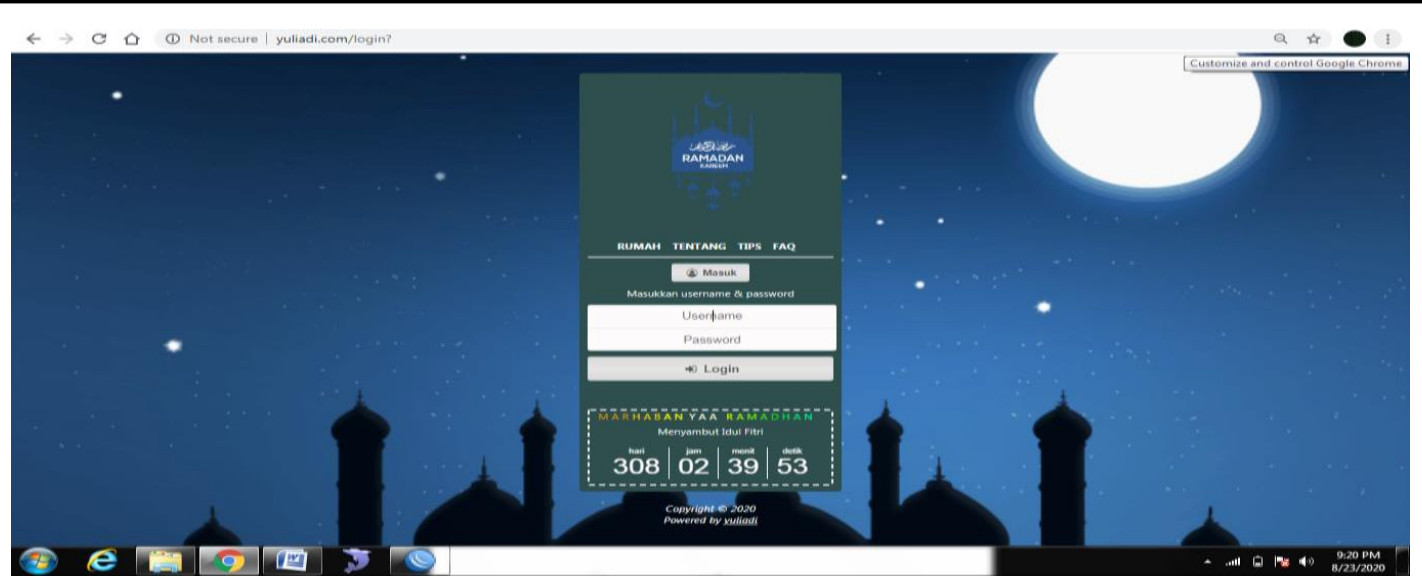

Gambar 7. Masuk jaringan

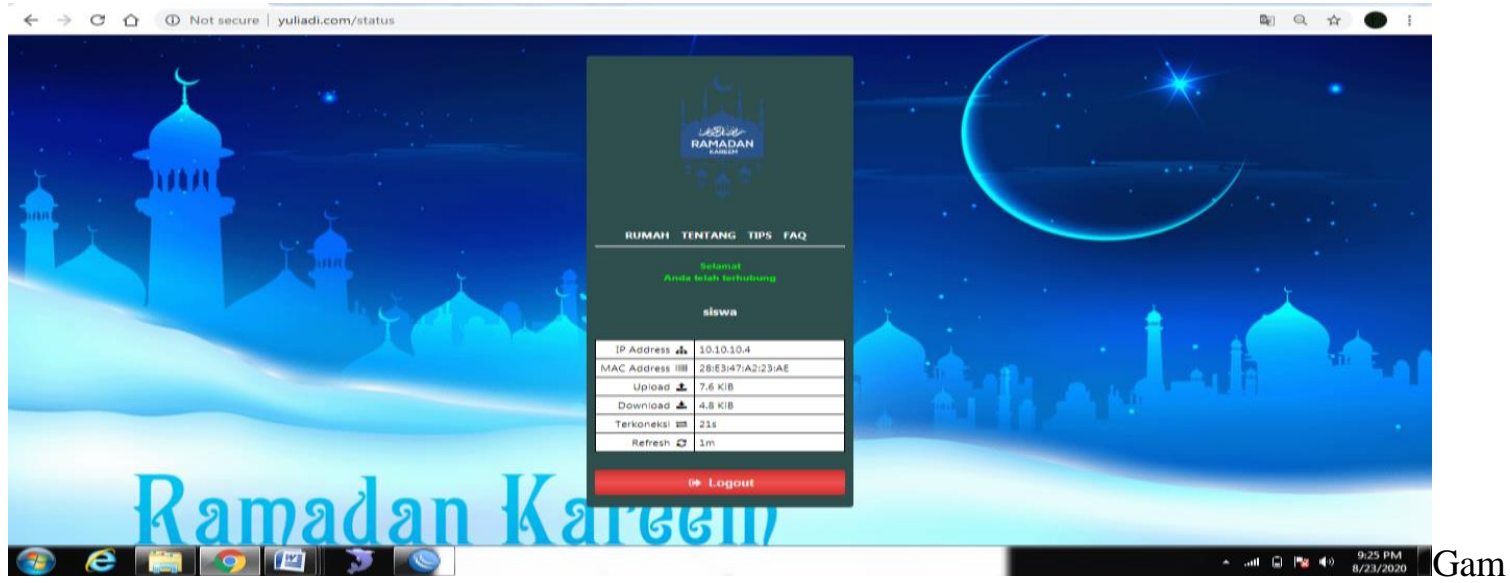

bar 8. Berhasil masuk jaringan
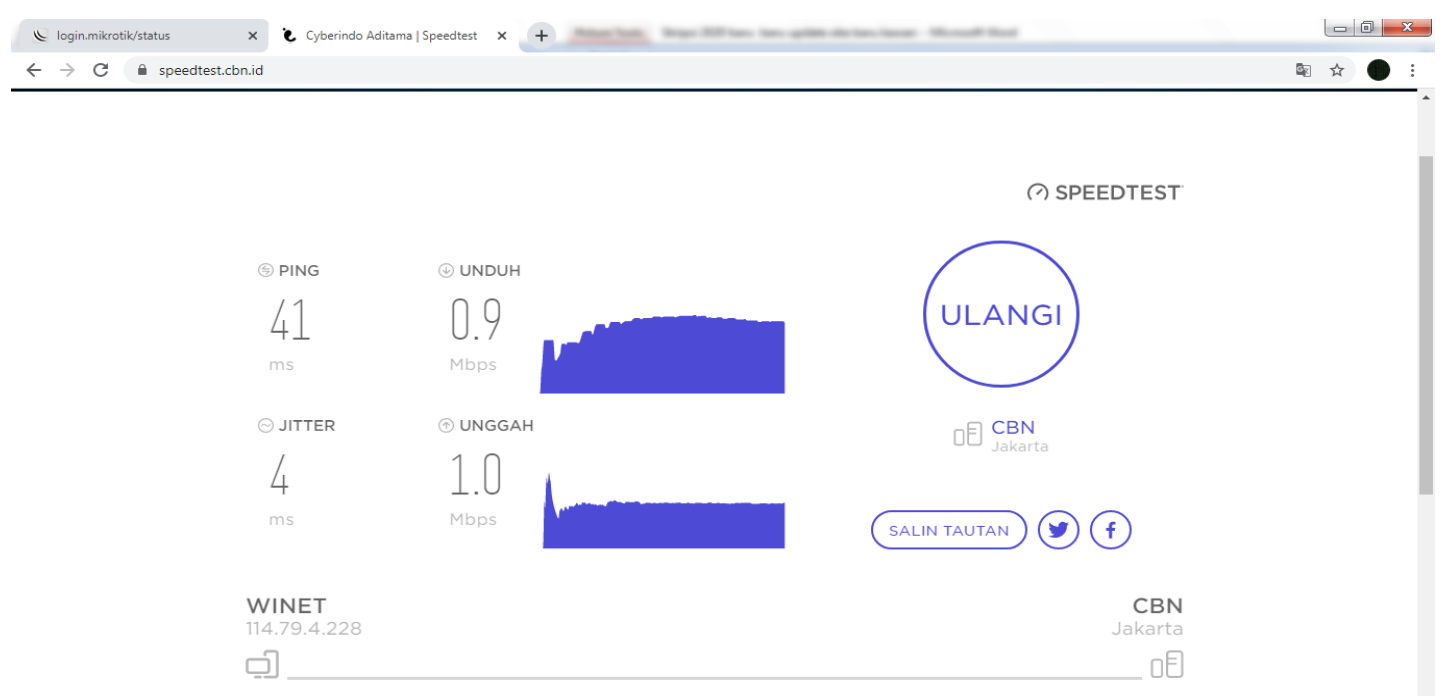

bar 9. Hasil bandwidth user 

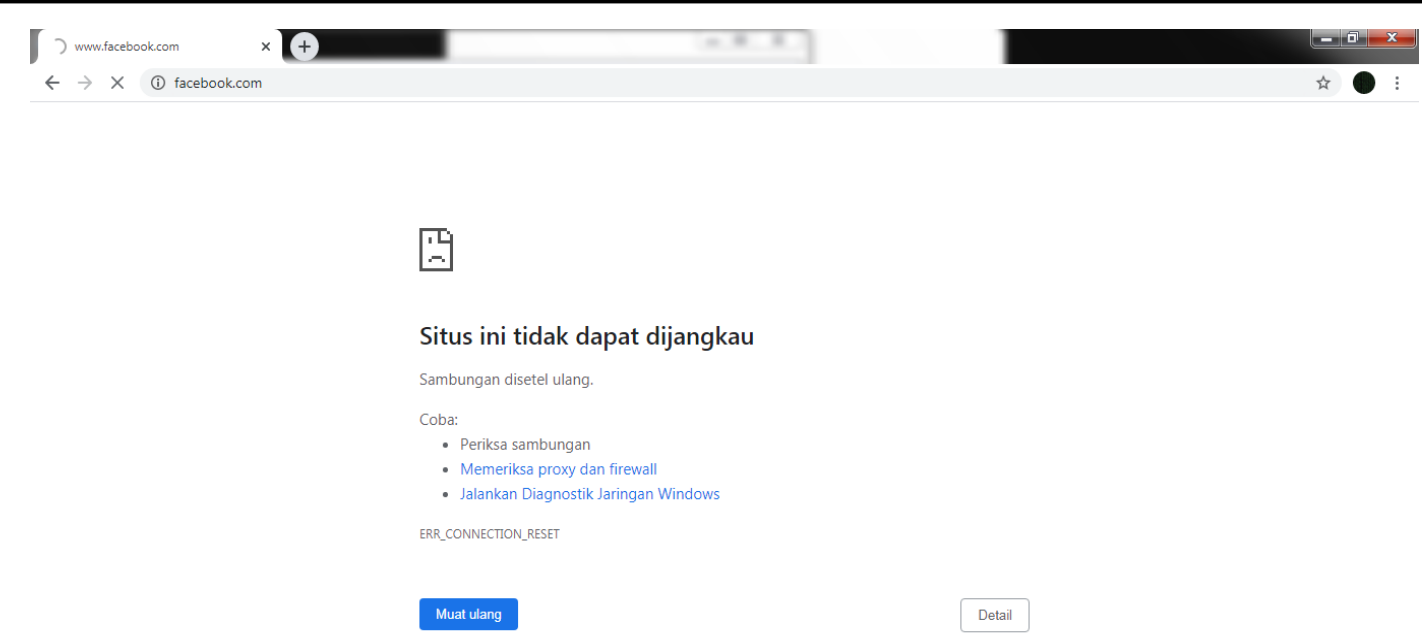

Gambar 10. Hasil blokir user

\section{PENUTUP}

Kesimpulan

Pada bagian ini berisikan kesimpulan dari hasil penelitian baik berupa angka numerik, kebijakan kualitatif atau variabel model hasil penelitian. Kesimpulan berisikan naskah teks paragraf dan tidak mengizinkan adanya gambar, persamaan (equation), dan tabel.

Setelah melakukan penelitian jaringan pada Ananda Islamic School. Penulis mendapatkan beberapa kesimpulan diantaranya sebagai berikut:

1. Router mikrotik RB 951UI-2HnD sebagai router usulan mampu mengatasi kekurangan router tp-link sebelumnya pada jaringan berjalan di Ananda Islamic School.

2. Metode packet-mark dan queue tree dapat menjadi solusi untuk pengaturan manajemen bandwidth pada Ananda Islamic School, karena admininistrator jaringan dapat dengan mudah memberikan bandwidth sesuai kebutuhan user.

3. Block Access Website berdasarkan user dapat menjadi solusi untuk administrator jaringan dalam menentukan user mana yang ingin diblokir website-nya pada jam, maupun hari tertentu.

\section{Saran}

Adapun beberapa saran yang mampu penulis berikan setelah memperoleh hasil penelitian untuk pembaca diantaranya sebagai berikut:

1. Untuk membuat blokir website di mikrotik selain menggunakan layer 7 protocol dapat pula menggunakan menu web proxy, dimana untuk layer 7 protocol dalam sistem mikrotik memiliki kelemahan yang dapat meningkatkan penggunaan memori pada router board mikrotik.

2. Untuk sistem keamanan jaringan di mikrotik perlu adanya penambahan seperti melakukan pencegahan port scanning, karena untuk serangan ini bekerja dengan cara memeriksa status port TCP pada jaringan mikrotik maupun mencari celah port yang terbuka lalu mencoba masuk ke sistem mikrotik tersebut.

3. Melakukan upgrade perangkat mikrotik router board dengan kapasitas RAM yang lebih besar dari sebelumnya karena untuk membuat penambahan fitur-fitur terbaru dalam mikrotik seperti user manager, maupun menggingat seiring berkembangnya teknologi maka harus di sesuaikan dengan versi terbaru. 


\section{DAFTAR PUSTAKA}

[1] D. Susianto, "Implementasi Queue Tree Untuk Manajemen Bandwidth Menggunakan Router Board Mikrotik," J. Cendikia, vol. 12, pp. 1-7, 2016.

[2] M. Husnaini, W. Bagye, and M. Ashari, "Implementasi Fitur Layer 7 Protocols Mikrotik Rb750 Di Smkn 1 Narmada," J. Inform. dan Rekayasa Elektron., vol. 2, p. 78, 2019, doi: 10.36595/jire.v2i1.94.

[3] A. Nasir, "Perancangan Layer-7 Packet Filtering Pada Jaringan Komputer Universitas Atma Jaya Makassar," J. Temat., vol. 6, pp. 93-100, 2018.

[4] Muntahanah, Y. Darnita, and R. Toyib, "Paper Block Akses Browsing Menggunakan Mikrotik Rb 751U-2Hnd Dengan Schedule Time (Studi Kasus: Disnakerpora Kota Bengkulu)," Sistemasi, vol. Volume 7 N, pp. 64-77, 2018.

[5] S. M. S. Qirom, "Rancang Bangun Jaringan Hotspot, Bandwidth Dan Blokir Website Berisi Konten Negatif Untuk Meningkatkan Layanan Pembelajaran Di Sd Negeri Bangun Galih 1," J. Power Elektron. J. Orang Elektro, vol. 6, p. 5, 2017, [Online]. Available: https://ejournal.poltektegal.ac.id/index.php/powerelektro/article/view/1188.

[6] R. Primartha, Manajemen Jaringan Komputer Teori dan Praktik. informatika Bandung, 2019.

[7] C. A. Pamungkas, "Manajemen bandwith menggunakan mikrotik routerboard di politeknik indonusa surakarta," Inf. Politek. Indonusa Surakarta, vol. 1, pp. 3-8, 2016.

[8] M. Purwahid, J. Triloka, and S. M. K. N. Sukadana, "Analisis Quality of Service ( QOS ) Jaringan Internet Untuk Mendukung Rencana Strategis Infrastruktur Jaringan Komputer Di SMK N I Sukadana," vol. 02, pp. 100-109, 2019. 